\title{
Melanonychia in children
}

\section{Ouiame EL Jouari, Ghita Senhaji, Salim Gallouj, Hanane Baybay, Fatima Zahra Mernissi}

\author{
Department of Dermatology, University Hospital Hassan II Fez, Morocco
}

Corresponding author: Dr. Ouiame EL Jouari, E-mail: eljouariouiame@gmail.com

A healthy 2 years-old-boy, with no family history of melanoma or other tumors. He was brought in consultation by his mother for evaluation of a congenital lesion of the nail of the thumb of the left hand. Physical examination showed a homogeneous erythematousbrown color band of the nail of the thumb of the left hand. Without hyperpigmentation of the proximal nail fold (Fig. 1). Dermoscopy revealed multiple homogeneous, narrow and regular longitudinal lines in the nail plate with some pigmented globules. Without periungual pigmentation (Fig. 2). Correlation of the age, the congenital onset, clinical and dermoscopic findings suggested melanocytic nevus of the nail matrix as the most likely diagnosis. Given the apparent benign nature of the lesion, close clinical and dermoscopic control was recommended. After 24 months of follow-up, the size of the lesion was unchanged.

Melanonychia is defined as a brown or black pigmentation on a nail as a result of melanin and other exogenous pigments [1]. In rare instances, congenital nevi present subungually, with fewer than 20 biopsy-proven cases reported [2]. Nail matrix nevus usually presents with longitudinal melanonychia, which is also observed in subungual melanoma or other benign conditions such as subungual lentigo. Pigment bands of Nail matrix nevus are well demarcated from adjacent uninvolved nail plate devoid of pigment and the nail plate surrounding the longitudinal melanonychia also presents with a background of brown pigmentation [3]. Hutchinson sign is defined by longitudinal melanonychia extending into the periungual tissues. Whereas it is one criterion for the $\mathrm{ABC}$ rule of subungual melanoma and is traditionally considered a worrisome feature, it is certainly not pathognomonic and a malignant cause should not be assumed without thorough assessment [2]. Dermoscopy is especially helpful in the differential diagnosis of nail pigmentations, because it can reduce unnecessary and

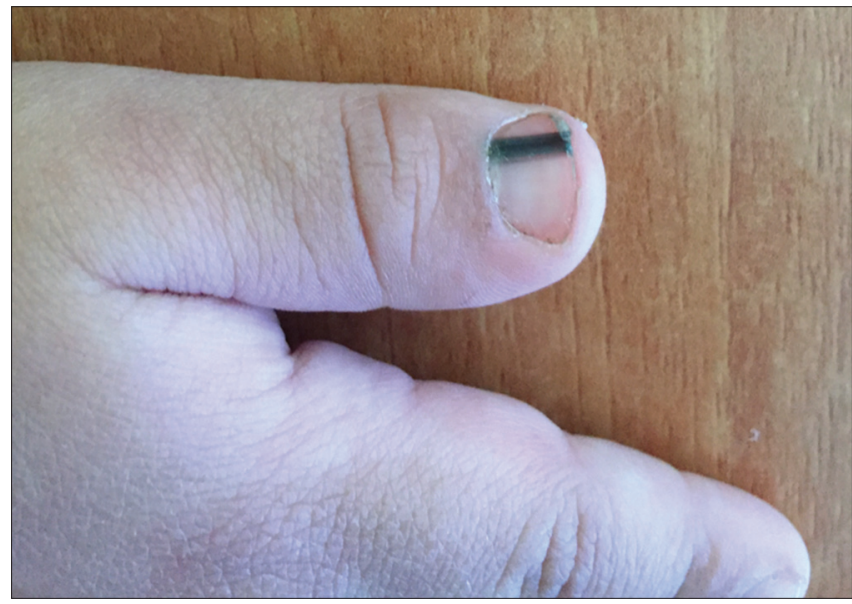

Figure 1: Homogeneous erythematous-brown color band of the nail of the thumb of the left hand.

invasive nail unit biopsy. It usually observed as a limited width of brown background with a regular pattern of the longitudinal lines. A previous dermoscopic study of adult and childhood NMNs found that pseudo-Hutchinson's sign, triangle sign, and globules were more frequent in childhood NMN and that Hutchinson's sign and irregular band pattern also tended to be more common in children [1]. The management of pigmented nail lesions will therefore depend on whether the rare but very serious childhood melanoma is suspected. In cases of melanonychia in which malignancy is suspected (a broad band of pigment, Hutchinson sign, irregular dermoscopic features, a dark-skinned patient), the lesion must be completely excised. Dermoscopic and clinical follow-up should be reserved for lesions with low-risk features (narrow bands, uniform dermoscopic characteristics, no changes overtime) [3].

\section{Consent}

The examination of the patient was conducted according to the Declaration of Helsinki principles.

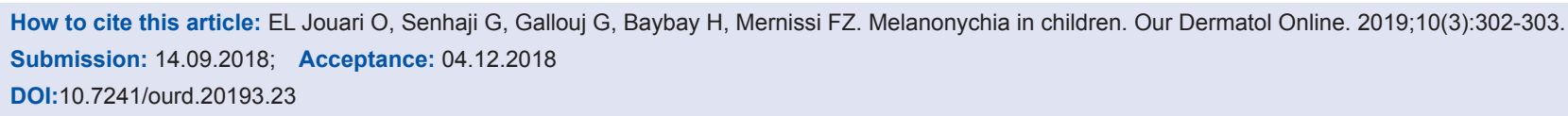




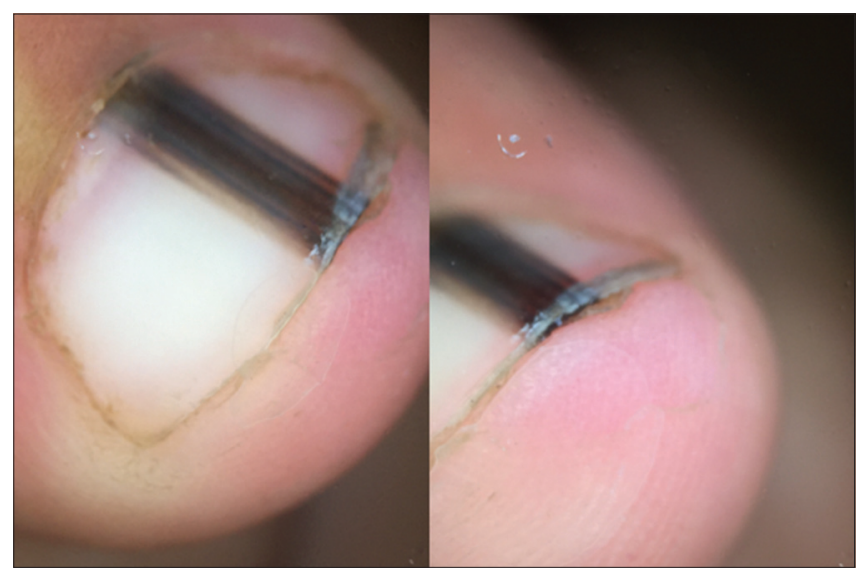

Figure 2: Homogeneous, narrow and regular longitudinal lines in the nail plate with some pigmented globules.

\section{REFERENCES}

1. Lee JH, Lim Y, Park JH, Lee JH, Jang KT, Kwon EJ, et al. Clinicopathologic features of 28 cases of nail matrix nevi (NMNs) in Asians: Comparison between children and adults. J Am Acad Dermatol. 2018;78:479-89.

2. Goldminz AM, Wolpowitz D, Gottlieb AB, Krathen MS. Congenital subungual melanocytic nevus with a pseudo-Hutchinson sign. Dermatol Online J. 2013;19:8.

3. Agusti-Mejias A, Messeguerb F, Febrera I, Alegre V. Nevus melanocítico congénito subungueal y periungueal. Actas Dermosifiliogr. 2013;104:446-8.

Copyright by Ouiame EL Jouari, et al. This is an open-access article distributed under the terms of the Creative Commons Attribution License which permits unrestricted use, distribution, and reproduction in any medium, provided the original author and source are credited.

Source of Support: Nil, Conflict of Interest: None declared. 